\title{
Assessment of Age and Duration of Symptoms on Outcomes of Emergency Scrotal Exploration for Acute Scrotal Pain
}

\author{
Ghulam Mustafa Nandwani1, Adeel Anwar2, Rajindra Singh², Alistair B Stewart2, James A Forster2 and Sanjai K Addla ${ }^{3}$ \\ 1Department of Urology, Ninewells Hospital and Medical School, Dundee, UK \\ 2 Department of Urology, Bradford Teaching Hospital, Bradford, UK \\ ${ }^{3}$ Department of Uro-Oncology, Apollo Cancer Institutes, Apollo Health City, Jubilee Hills, Hyderabad, India
}

\begin{abstract}
Objective: To study the effects of age and duration of symptoms on the outcomes of scrotal explorations for acute scrotal pain at our institution.

Study Design: Case series.

Place and Duration of Study: Bradford Teaching Hospital NHS Trust, from January 2006 to December 2017.

Methodology: Retrospective data was collected from electronic case records of the patients who required scrotal exploration for suspected torsion of the testis. Group difference between continuous variables (age and duration of symptoms) were assessed by Kruskal Wallis and independent samples Mann-Whitney U-tests. The Fisher Exact and Chisquare tests were used to analyse relationships between categorical data.

Results: In total, 502 patients required scrotal exploration. The median age (years) and duration of symptoms (hours) were 16.4 years $(1.3-77)$ and 4 hours $(1-336)$, respectively. Torsion of the testis was found in $231(46 \%)$, torsion of the testicular appendix in $126(25 \%)$, epididymal inflammation in $46(9.2 \%)$, and no cause identified in $99(19.7 \%)$. Immediate orchidectomy for non-viable testis performed in 34 (14.7\% of TT group and $6.8 \%$ of the overall cohort). Duration of symptoms was significantly associated with risk of orchidectomy in torsion patients 4 vs. 27 hours $(p<0.0001)$. Overall 47 $(9.3 \%)$ patients presented after 12 hours, $22(46.8 \%)$ had TT. There were $13(2.6 \%)$ patients older than 40 years and 8 $(61.5 \%)$ of these had torsion.

Conclusion: The most commonest diagnosis for patients presenting with acute scrotal pain was torsion of the testis followed by torsion of appendix testis. Testicular salvage was inversely related to the duration of symptoms. Patient's age did not predict the need for orchidectomy. This data supports the practice of urgent scrotal exploration for acute scrotal pain with a clinical suspicion of torsion regardless of age and duration of symptoms.
\end{abstract}

Key Words: Spermatic cord torsion, orchiectomy, orchidopexy, necrosis.

How to cite this article: Nandwani GM, Anwar A, Singh R, Stewart AB, Forster JA, Addla SK. Assessment of age and duration of symptoms on outcomes of emergency scrotal exploration for acute scrotal pain. J Coll Physicians Surg Pak 2020; 30(2):201-204.

\section{INTRODUCTION}

Acute testicular torsion (TT) is a urological emergency requiring testicular exploration. Reported incidence is 1.1 - 3.5 per 100,000 with the highest incidence in the ages of $10-19$ years. ${ }^{1-3}$ The commonest type is an intravaginal type, typically occurs during puberty and mostly related to "bell-clapper deformity", which is a congenital malformation of the processus vaginalis. ${ }^{3}$ TT usually occurs without any precipitating cause.

The ischemic damage is dependent on duration of TT (time between onset of pain and de-torsion) and degree of twisting of the spermatic cord (SC). ${ }^{4}$ Necrotic testis is found in all cases of SC torsion greater than $360^{\circ}$ and symptom duration of greater than 24 hours. 5,6

Correspondence to: Dr. Ghulam Mustafa Nandwani,

Department of Urology, Ninewells Hospital and Medical School,

Dundee, $U K$

E-mail:drgmnandwani@yahoo.com

Received: July 30, 2019; Revised: November 18, 2019;

Accepted: November 28, 2019
The aim of this study was to determine the outcomes of acute scrotal exploration (SE) by correlating intraoperative findings with duration of symptoms and age of the patient.

\section{METHODOLOGY}

The study was approved by Department of Urology, Bradford Teaching Hospital NHS Trust, and the data was collected retrospectively from case notes and electronic records on patients from January 2006 to December 2017. All patients regardless of age who required SE for TT were included. Patients with incomplete records were excluded. Data were collected for demographics, clinical history, duration of symptoms, intraoperative findings, and need for orchidectomy.

The standard surgical approach involved untwisting of the SC, and if testicular viability was questionable then the testis was wrapped in warm saline soaked gauze. During that time, the contralateral testis was explored, fixed with three-point fixation using non-absorbable suture; and then reassessment of the previously de- 
torted testis was done to check signs of viability. This gave at least 20 to 25 minutes for the testis to regain its blood flow and if it remained non-viable then orchidectomy was performed. Follow-up investigations for patients in whom the testis was left in situ with doubtful viability included clinical examination and ultrasound scan with colour doppler studies at 4 to 6 weeks' time to assess the viability of the testis.

Statistical analysis was done by using IBM SPSS Statistics Software version 22, statistical significance was considered at $p<0.05$. Group difference between continuous variables (age and duration of symptoms) were assessed by Kruskal Wallis and independent samples Mann-Whitney U-tests. The Fisher Exact and Chi-square tests were used to analyse relationships between categorical data.

\section{RESULTS}

In total, 502 patients required acute SE for suspected torsion of the testis. The median age at presentation and duration of symptoms were 16.4 years (range $1.3-77$ ) and 4 hours (range 1 - $336 \mathrm{hr}$ ), respectively. Right-sided explorations were performed in 237 (47.2\%), while 265 $(52.8 \%)$ underwent left-sided exploration. Operative findings concluded TT in 231 (46\%), TTA in 126 (25\%), epididymal inflammation (EI) in $46(9.2 \%)$ and no cause identified $(\mathrm{NCl})$ in $99(19.7 \%)$. Median ages for TT, TTA, $\mathrm{El}$ and $\mathrm{NCl}$ were 16, 11, 21 and 12.5 years, respectively. There was a significant association of age with the final diagnosis $(p<0.0001)$ [Table I]. Diagnosis of TTA was made in the youngest cohort, followed by $\mathrm{NCl}$ and TT. Orchidectomy for non-viable testis required in $34,(6.8 \%$ of overall and $14.7 \%$ of TT patients).

For the TT group $(\mathrm{n}=231)$, the median age and duration of symptoms were $16(3-77)$ years and $4(1.5-336)$ hours, respectively. Orchidectomy was required in 34 $(14.7 \%)$ for non-viable testes, whilst $197(85.3 \%)$ testes were salvaged. There was no difference in the median age (years) at presentation between the non-orchidectomy vs. orchidectomy groups, 15.8 years $(3-77)$ vs. 16.9 years $(3.4-60)$, respectively $(p=0.3)$. However, the median duration of symptoms (hours) were markedly different between non-orchidectomy vs. orchidectomy groups, 4 hours (1.5 - 32) vs. 27 hours (2 - 168), respectively ( $p<0.0001)$. In total, $180(78 \%)$ presented 6 hours (Group 1), 29 (12.5\%) between 6 to 12 hours (Group 2) and $22(9.5 \%)$ after 12 hours (Group 3) [Figure 1]. Testicular salvage was achieved in $175(97.2 \%)$ and 21 (72.4\%) in Group1 and Group 2, respectively. Only one patient from the Group 3 cohort had his testicle salvaged $(4.5 \%)$ [Figure 2].

Overall, $47(9.3 \%)$ patients presented after 12 hours of onset of symptoms and 22 (46.8\%) were diagnosed with TT, while $25(53.2 \%)$ had other diagnosis where most common finding was TAT (Figure 1). In total, 488 (97.2\%) were $<40$ years and TT was found in $45.7 \%$ of these while $14(2.8 \%)$ were $>40$ years and TT was found in 8 $(57.15 \%)$. Majority $(75 \%$ of $>40$ years) presented within 6 hours duration. Testicular salvage achieved in $83 \%$ vs. $62.5 \%$ in $<40$ years vs. $>40$ years, respectively.

Bilateral TT was found in $3(0.6 \%)$. In the first case contralateral, synchronous torsion was found when scrotum opened for testicular fixation. The second case had intermittent bilateral testicular pain, TT found on exploration bilaterally and bilateral testicular fixation performed. Finally, the third case was initially diagnosed with suspected epididymoorchitis but re-presented after

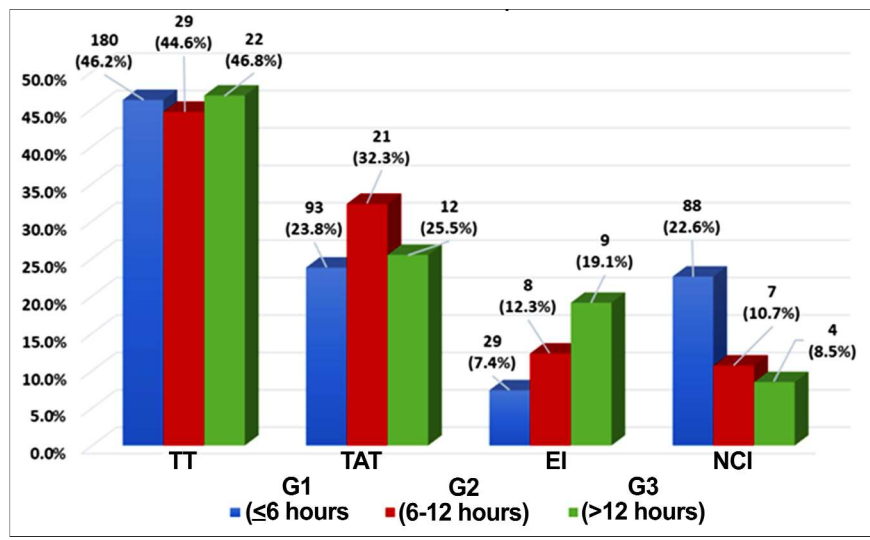

Figure 1: Outcomes of acute scrotal explorations in relation to duration of symptoms.

Table I: Summary of results for acute scrotal exploration (Jan 2006 - Dec 2017).

\begin{tabular}{|c|c|c|c|}
\hline Total explorations & 502 & & \\
\hline Age (years) & Median $14,(1.3$ to 77$)$ IQR 9 & & \\
\hline Duration of symptoms (hrs) & Median 4, (1 to 336) IQR 3 & & \\
\hline \multicolumn{4}{|l|}{ Side of exploration (first) } \\
\hline Right & $237(47.2 \%)$ & & \\
\hline Left & $265(52.8 \%)$ & & \\
\hline Aetiology & & Age (years) & Symptoms (hours) \\
\hline Torsion & $231(46 \%)$ & Median 16, (3 - 77) IQR 8.6 & Median 4, (1.5 - 336) IQR 3 \\
\hline Torsion of appendix testis & $126(25 \%)$ & Median 11, (1.3 - 24) IQR 4.3 & Median 4.2, (1.5 - 96) IQR 3.6 \\
\hline Epididymal inflammation & $46(9.2 \%)$ & Median 21, (5 - 54) IQR 16 & Median 5, (2.5 - 48) IQR 6.4 \\
\hline \multirow[t]{2}{*}{ No cause identified } & $99(19.7 \%)$ & Median 12.5, (5 - 56) IQR 12 & Median 4, (1 - 72) IQR 2 \\
\hline & & $p<0.0001 \$$ & p $0.001 \$$ \\
\hline Orchidectomy (when TT was detected) & $34(15 \%)$ & & \\
\hline
\end{tabular}


Table II: Comparison of results of current study with other published studies.

\begin{tabular}{|c|c|c|c|c|c|c|}
\hline Study & Total explored & Torsion testis & $\begin{array}{c}\text { Torsion of } \\
\text { appendix testis }\end{array}$ & $\begin{array}{l}\text { Orchidectomy in } \\
\text { esticular torsion }\end{array}$ & $\begin{array}{c}\text { Other causes } \\
\text { (Inflammation etc.) }\end{array}$ & No cause found \\
\hline Van $1999(18)$ & 543 & $23.4 \%$ & $46 \%$ & $9.4 \%$ & $23.3 \%$ & $7.2 \%$ \\
\hline Mushtaq 2003 (17) & 187 & $21.3 \%$ & $56 \%$ & $20 \%$ & $19.7 \%$ & $3 \%$ \\
\hline Murphy 2006 (16) & 121 & $27 \%$ & $57 \%$ & $29 \%$ & $16 \%$ & $6.6 \%$ \\
\hline Molokwu 2011 (21) & 173 & $51 \%$ & $24 \%$ & $18 \%$ & $14 \%$ & $10 \%$ \\
\hline Makela $2007(20)$ & 388 & $26 \%$ & $45 \%$ & & $29 \%$ & - \\
\hline Nason 2013 (15) & 155 & $46.5 \%$ & $30.3 \%$ & $50 \%$ & $20 \%$ & $3.3 \%$ \\
\hline Current series 2019 & 502 & $46 \%$ & $25 \%$ & $15 \%$ & $11.6 \%$ & $17.3 \%$ \\
\hline
\end{tabular}

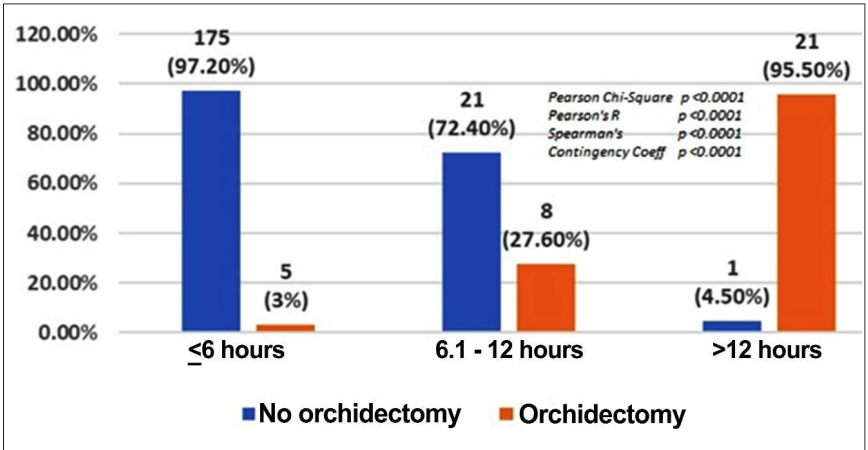

Figure 2: Testicular salvage rate in relation to duration of symptoms.

a few days with non-resolving pain and new onset of pain for the last 6 hours in the contralateral testis. At first SE performed on the new onset painful side, which showed very dusky testis with very little improvement in colour after detorsion. Before considering orchidectomy, other side was explored which also showed severely necrotic testis and orchidectomy performed. Orchidectomy was not performed on the originally explored side with the view that he may get some improvement in blood flow which may achieve hormonal function.

\section{DISCUSSION}

Anderson reported the outcomes of TT on 670 patients which is the largest series from the UK. ${ }^{7}$ The present series provides a valuable contemporary update on the outcomes of acute SE in all age groups (Table II). All the patients with acute SE for suspected TT were included. The median age was 14 years and $25 \%$ of the study population was older than 20 years. TT was the commonest diagnosis (46\%) followed by TTA $(25 \%)$. Median age was higher in TT (16 years) in comparison to TTA (11 years). In this series, the frequency of TTA was lower in comparison to other series $(40 \%-57 \%)$. This difference could be due to the inclusion of younger age group patients in this cohort and these results are comparable to more recent publications (Table II).8,9 The final diagnostic results from this series were comparable to the studies by Molokwu and Nason, who showed TT $51 \%$ and TAT $24 \%$, and TT $46.5 \%$ and TAT $30.3 \%$ ), respectively. 10,11

Bilateral adolescent testicular torsion is rare and simultaneous bilateral torsion is extremely rare.12,13 In our series, 3 patients $(0.6 \%)$ had bilateral torsion. This emphasises that contralateral testis should be explored before performing orchidectomy for non-viable testis secondary to TT.

The frequency of immediate orchidectomy in TT ranges between $10 \%$ - 50\%.7,9-11,14,15 In our study, orchidectomy for non-viable testis required in $14.7 \%$. Patients with TT greater than 10 hours' duration are most likely to develop significant testicular necrosis. ${ }^{16,17}$ Cummings reported, that patients with non-salvageable testes presented significantly late (105 vs. 7.7 hours), had greater delays in SE (7.5 vs. 1.5 hours) and higher degrees of torsion (630 vs. 412 degrees. ${ }^{18}$ This study also shows that an increased duration of symptoms was significantly associated with the likelihood of orchidectomy in patients with TT. Testicular salvage was possible for $97.2 \%$ of the patients presenting within 6 hours, whilst it was only possible in $4.5 \%$ of the patients presenting after 12 hours from the onset of symptoms.

Studies have shown variable association of age and non-viable testis in TT. Mansbach reported that orchidectomy was required in $41 \%$ (18 to 25 years) in comparison to $19 \%$ (1 to 9 years). But, duration of symptoms was not reported in this study. ${ }^{19}$ Barada found $\geq 18$ years had lower orchidectomy rate vs. $<18$ years, $8 \%$ vs. $44 \%$, respectively. The main reason for a higher orchidectomy rate was a delay in presentation in younger patients, 20 hours vs. 4 hours, $p<0.001(3)$. Cummings reported $70.3 \%$ salvage rates for patients under 21 years and $41 \%$ for over 21 years, which was related to delay in management and degree of torsion. ${ }^{18}$ Age itself was not a significant factor for orchidectomy. Importantly, it was the delay in seeking medical advice and management of TT were associated with higher orchidectomy rates. ${ }^{3,18,19}$ This study did not demonstrate association of age with orchidectomy with median age being 15.8 years for the orchidectomy group compared to 16.9 years in non-orchidectomy cohort, $(p=0.3)$. It was also noted that $2.8 \%$ of patients were $\geq 40$ years and the commonest diagnosis was TT $(57 \%)$, testicular salvage was $62.5 \%$ and $75 \%$ presented within 6 hours of the onset of symptoms. This could be related to general awareness of the condition in this age cohort, with patients self-presenting to emergency department or seeking urgent opinion from a general practitioner. The need for orchidectomy due to late hospital presentations 
could be reduced by increasing the general awareness of the condition among public, health education to parents, and young males. In all cases, prompt surgical intervention and detorsion plays a vital role.5,8,16

Early presentation after the onset of symptoms; and urgent scrotal exploration are the keys to avoid orchidectomy. TT was also the commonest diagnosis in patients older than 40 years presenting with acute scrotal pain. Finally, patients with TT were older than patients with TTA, but this difference does not alter the decision for scrotal exploration. This could be useful in counselling of patients and their parents at the time of consent.

\section{CONCLUSION}

This data supports the practice of urgent scrotal exploration for acute scrotal pain with a clinical suspicion of torsion. TT was the most common finding followed by TTA. Testicular salvage was associated with the duration of symptoms; and age was not a predictor of diagnosis or need for orchidectomy.

\section{CONFLICT OF INTEREST:}

None of the contributing authors have any conflicts of interest, including specific financial interests or relationships and affiliations relevant to the subject.

\section{AUTHORS' CONTRIBUTION:}

GMN: Concept, design, data collection, analysis, interpretation of data, critical revision.

AA: Data collection, review of literature, drafting of work. RS, ABS: Revision for intellectual contents, drafting, looking through results.

JAF, SKA: Drafting the work, interpretation of results and revising it critically for important intellectual content.

\section{REFERENCES}

1. Lee SM, Huh JS, Baek M, Yoo KH, Min GE, Lee HL, et al. A nationwide epidemiological study of testicular torsion in Korea. J Korean Med Sci 2014; 29:1684-7.

2. Huang WY, Chen YF, Chang HC, Yang TK, Hsieh JT, Huang KH. The incidence rate and characteristics in patients with testicular torsion: A nationwide, population-based study. Acta Paediatr Int J Paediatr 2013; 102:363-7.

3. Barada JH, Weingarten JL, Cromie WJ. Testicular salvage and age-related delay in the presentation of testicular torsion. J Urol 1989; 142:746-8.
4. Oktar T, Kucukdurmaz F, Erdem S, Kilicaslan I, Ceylan C, Sanli O, et al. Tunica albuginea decompression fails to alter the injury of prolonged arterial occlusion during testicular torsion. $J$ Urol 2013; 190:239-43.

5. Lorenzini F, Tambara Filho R, Gomes RPX, Martino-Andrade AJ, Erdmann TR, Matias JEF. Long-term effects of the testicular torsion on the spermatogenesis of the contralateral testis and the preventive value of the twisted testis orchiepididymectomy. Acta Cir Bras 2012; 27:388-95.

6. Moritoki Y, Kojima Y, Mizuno K, Kamisawa H, Kohri K, Hayashi Y. Intratesticular pressure after testicular torsion as a predictor of subsequent spermatogenesis: A rat model. BJU Int 2012; 109: 466-70.

7. Anderson JB, Williamson RCN. Testicular torsion in Bristol: A 25-year review. Br J Surg 1988; 75:988-92.

8. Murphy FL, Fletcher L, Pease P. Early scrotal exploration in all cases is the investigation and intervention of choice in the acute paediatric scrotum. Pediatr Surg Int 2006; 22:413-6.

9. Van Glabeke E, Khairouni A, Larroquet M, Audry G, Gruner M. Acute scrotal pain in children: Results of 543 surgical explorations. Pediatr Surg Int 1999; 15:353-7.

10. Molokwu CN, Somani BK, Goodman CM. Outcomes of scrotal exploration for acute scrotal pain suspicious of testicular torsion: A consecutive case series of 173 patients. BJU Int 2011; 107:990-3.

11. Nason GJ, Tareen F, McLoughlin D, McDowell D, Cianci F, Mortell A. Scrotal exploration for acute scrotal pain: A 10-year experience in two tertiary referral paediatric units. Scand $J$ Urol 2013; 47:418-22.

12. Beliaev AM, Mundy I. Bilateral simultaneous testicular torsion presenting as a diagnostic dilemma. BMJ Case Rep 2013; 2013:bcr2013010137.

13. Benge BN, Eure GR, Winslow BH. Acute bilateral testicular torsion in the adolescent. J Urol 1992; 148:134.

14. Mushtaq I, Fung M, Glasson MJ. Retrospective review of paediatric patients with acute scrotum. ANZ J Surg 2003; 73:55-8.

15. Mäkelä E, Lahdes-Vasama T, Rajakorpi H, Wikström S. A 19-year review of paediatric patients with acute scrotum. Scand J Surg 2007; 96:62-6.

16. Visser AJ, Heyns CF. Testicular function after torsion of the spermatic cord. BJU Int 2003; 92:200-3.

17. Lewis AG, Bukowski TP, Jarvis PD, Wacksman J, Sheldon CA. Evaluation of acute scrotum in the emergency department. J Pediatr Surg 1995; 30:277-82.

18. Cummings JM, Boullier JA, Sekhon D, Bose K. Adult testicular torsion. J Urol 2002; 167:2109-10.

19. Mansbach JM, Forbes P, Peters C. Testicular torsion and risk factors for orchiectomy. Arch Pediatr Adolesc Med 2005; 159: 1167-71. 